\title{
An experimental investigation into the effects of fin structure and surface type on the efficiency of heat exchangers used for dehumidification
}

\author{
G. $\operatorname{Sir}^{1}$, Ö. Balioğlu ${ }^{2} \&$ S. U. Onbaşığ lu ${ }^{3}$ \\ ${ }^{1} R \& D$ Engineer, Cleaning Technologies Department, Arçelik A.Ş, Turkey \\ ${ }^{2} R \& D$ Engineer, Thermodynamic Technologies Department, \\ Arçelik A.Ş, Turkey \\ ${ }^{3}$ Department of Mechanical Engineering, \\ Istanbul Technical University, Turkey
}

\begin{abstract}
Household tumble dryers are classified into three major categories according to their dehumidification process. Air vented dryers are the most simple and least efficient ones, in which humid air is directly vented to the outside environment, while the condenser tumble dryers have closed air loop with an air-to-air heat exchanger for dehumidification process. Heat pump tumble dryers are the most efficient products in domestic household dryers. In the heat pump systems of these dryers, the heat released from the condenser is used directed to the laundry and evaporator is used for the dehumidification of the humid air leaving the tumble. From the design point of the view, evaporator structure and dehumidification performance have a critical role on improving the heat pump dryer efficiency.

In this study, effect of fin type and fin coating of an evaporator which is used for dehumidification process in terms of condensation rate and efficiency has been studied. In order to study the effect of these parameters on dehumidification performance, temperature and air velocity at the inlet of evaporator (respectively $38^{\circ} \mathrm{C}$ and $1.85 \mathrm{~m} / \mathrm{s}$ ) has been kept constant while varying the relative humidity $(65 \%, 70 \%, 80 \%)$ of inlet air, fin type (plain and wavy) and surface type (hydrophobic and hydrophilic) of evaporators.

Keywords: heat pump, evaporator, hydrophobic, hydrophilic, surface coating, tumble dryer.
\end{abstract}




\section{Introduction}

Due to global warming and limited natural resources; efficient use of energy becomes the focus of both academic and industrial research. The common goal of manufacturers of different products is to design and produce less energy consuming products.

Recently heat pump systems have started to be adapted on household tumble dryers for improving energy efficiency. In this system, the tasks of the condenser and evaporator are to heat the laundry, dehumidify the humid air leaving the tumble, respectively. From the design point of the view, evaporator structure and dehumidification performance have a critical role on improving the heat pump dryer energy efficiency.

Most of the studies that have informed evaporator design in heat pump systems involve experimental and numerical approaches, such as Huzayyin et al. [1]; Wang et al. [2]; Pirompugd et al. [3]; Ma et al. [4].

Huzayyin et al. investigated the airside heat and mass transfer and fluid flow characteristics of a wavy-finned-tube direct expansion air coil, experimentally under cooling and dehumidifying conditions. Experiments were carried out to study the effects of operating conditions such as: air temperature, air relative humidity, air inlet velocity, and evaporator pressure on the airside performance (cooling capacity, dehumidification capacity, pressure drop, and heat transfer coefficient) of the coil [1].

Wang et al. highlighted heat and mass transfer characteristics of fin-and-tube heat exchangers with and without hydrophilic coating. For dehumidifying test conditions, the effect of hydrophilic coating on the sensible heat transfer coefficients is negligible, and there are no detectable changes of the sensible heat transfer coefficients due to inlet relative humidity value. However, the pressure drops for the hydrophilic coated surfaces are sensitive to the inlet relative humidity [2].

Pirompugd et al. reported correlations which are proposed for the wet surface ratio of a fin-and-tube heat exchanger with plain and wavy fin geometry under dehumidifying conditions [3].

Ma et al. presented the airside heat transfer and friction characteristics of 14 enhanced fin-and-tube heat exchangers with hydrophilic coating under wet conditions [4].

In this study, effect of fin type and fin coating of an evaporator which is used for dehumidification process in terms of condensation rate and efficiency has been studied. In order to study the effect of these parameters on dehumidification performance, temperature and air velocity at the inlet of evaporator (respectively $38^{\circ} \mathrm{C}$ and $1,85 \mathrm{~m} / \mathrm{s}$ ) has been kept constant while varying the relative humidity $(65 \%, 70 \%, 80 \%)$ of inlet air, fin type (plain and wavy) and surface type (hydrophobic and hydrophilic) of evaporators. 


\section{Experimental setup}

The schematic diagram of the experimental air circuit assembly is shown in Figure 1. It consists of a closed air loop in which air circulated by a centrifugal fan. Pressure transducers are used to measure the refrigerant side evaporation and condensation pressure to calculate enthalpy values. Heater and condenser are used to keep the air temperature constant at the inlet of the evaporator.

Wetted laundry bulk has also used to keep air humidity at a constant level at the inlet of the evaporator. For different air inlet relative humidity values, the amount of humidity of the laundries was changed. The test conditions of the system are as follows:

Dry-bulb temperatures of the inlet air: $38^{\circ} \mathrm{C}$

Inlet relative humidity for the incoming air: $65 \%, 70 \%, 80 \%$

Inlet air velocity: $1.85 \mathrm{~m} / \mathrm{s}$

Evaporation temperature (refrigerant side): $22{ }^{\circ} \mathrm{C}$

The aforementioned test conditions are at approximate values encountered with the household tumble dryers.

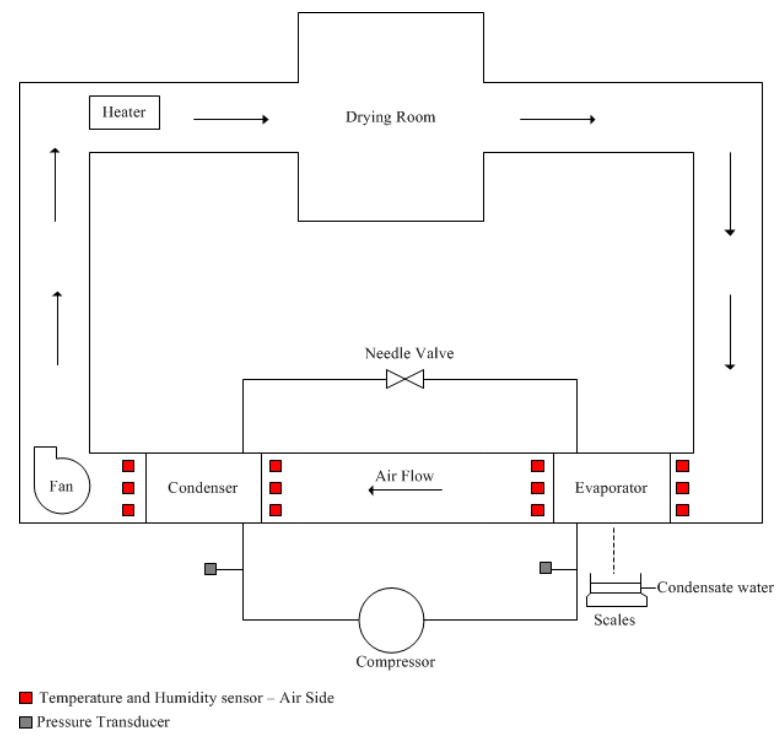

Figure 1: Schematic of the experimental set-up.

The refrigerant side thermocouple layout on evaporator and condenser are shown in Figure 2. In order to measure evaporator coil temperature, measurements were carried out on 10 different tube bends with thermocouples. Condenser side temperature measurements have been carried out at 3 different locations for further thermodynamics calculations. During experiments, 
evaporator coil temperature has been kept constant with the phase changing refrigerant. For the calculation of the evaporator inlet conditions, it is assumed that throttling inside the capillary tube has been occurred.

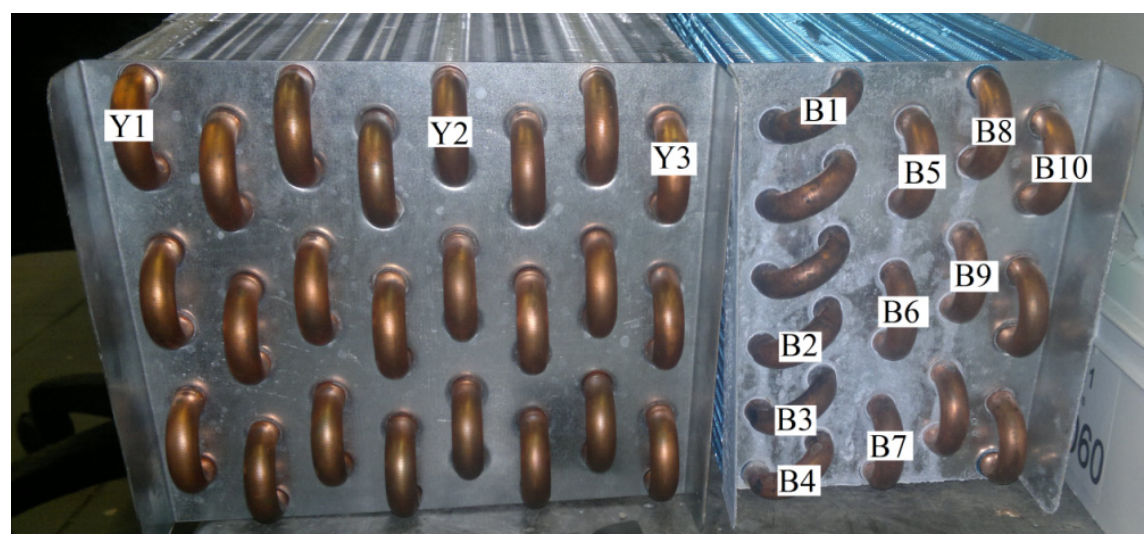

Figure 2: Schematic of the refrigerant side thermocouple layout on evaporator and condenser. (B: Evaporator, Y: Condenser).

In order to validate dehumidification calculations, a weight scale has been used to measure the water which is dehumidified on evaporator simultaneously.

\section{Results and discussions}

Dehumidification efficiency can be described by the equation:

$$
\eta_{\text {dehumidification }}=\frac{\dot{m}_{\text {water }} x\left(h_{g}-h_{f}\right)}{\dot{m}_{\text {ref }} x\left(h_{e o}-h_{c o}\right)}
$$

where $\dot{m}_{\text {water }}$ represents condensated vapor mass flow rate $(\mathrm{kg} / \mathrm{s}), h_{g}$ is the saturated vapor enthalpy $(\mathrm{kJ} / \mathrm{kg}), h_{f}$ is the saturated liquid enthalpy $(\mathrm{kJ} / \mathrm{kg}), \dot{m}_{r e f}$ represents refrigerant mass flow rate $(\mathrm{kg} / \mathrm{s}), h_{e o}$ represents evaporator outlet enthalpy $(\mathrm{kJ} / \mathrm{kg}), h_{c o}$ represents condenser outlet enthalpy $(\mathrm{kJ} / \mathrm{kg})$.

Moisture extraction rate (MER) is described by the equation:

$$
\operatorname{MER}(g r / s)=\frac{\dot{m}_{\text {air }} x\left(w_{i}-w_{o}\right)}{\Delta t}
$$

where $\dot{m}_{\text {air }}$ represents dry air mass flow rate $(\mathrm{kg} / \mathrm{s}), w_{i}$ represents specific humidity at the evaporator inlet $\left(g r_{\mathrm{H}_{2} \mathrm{O}} / \mathrm{kg}_{\text {dryair }}\right), w_{\mathrm{O}}$ represents specific humidity at the evaporator outlet $\left(g r_{\mathrm{H}_{2} \mathrm{O}} / \mathrm{kg}_{\text {dryair }}\right) . w_{i}$ and $w_{\mathrm{O}}$ are calculated depending on temperature, relative humidity and pressure values from the psychometric equations.

Experiments have been conducted according to the test matrix which is given in Table 1. 
Table 1: Test conditions matrix for experiments.

\begin{tabular}{|c|c|c|c|c|}
\hline Evaporator Type & $\begin{array}{c}\text { Air Inlet } \\
\text { Temperature } \\
\left({ }^{\circ} \mathrm{C}\right)\end{array}$ & \multicolumn{3}{|c|}{ Air Inlet Relative Humidity (\%) } \\
\hline Hydrophobic/Plain & 38 & 65 & 70 & 80 \\
\hline Hydrophobic/Wavy & 38 & 65 & 70 & 80 \\
\hline Hydrophilic/Plain & 38 & 65 & 70 & 80 \\
\hline Hydrophilic/Plain & 38 & 65 & 70 & 80 \\
\hline
\end{tabular}

Dehumidification process in heat pump dryers has three main phases (Figure 3). In Phase 1, the laundry and the components of dryer start to heat up so the dehumidification rate increases almost linearly. Phase 2 which may refer as active (or developed) dehumidification phase, dehumidification rate reaches the maximum level at a constant rate. At the final stage, in phase 3, since moisture level on the laundry decreases, the dehumidification rate decreases almost linearly.

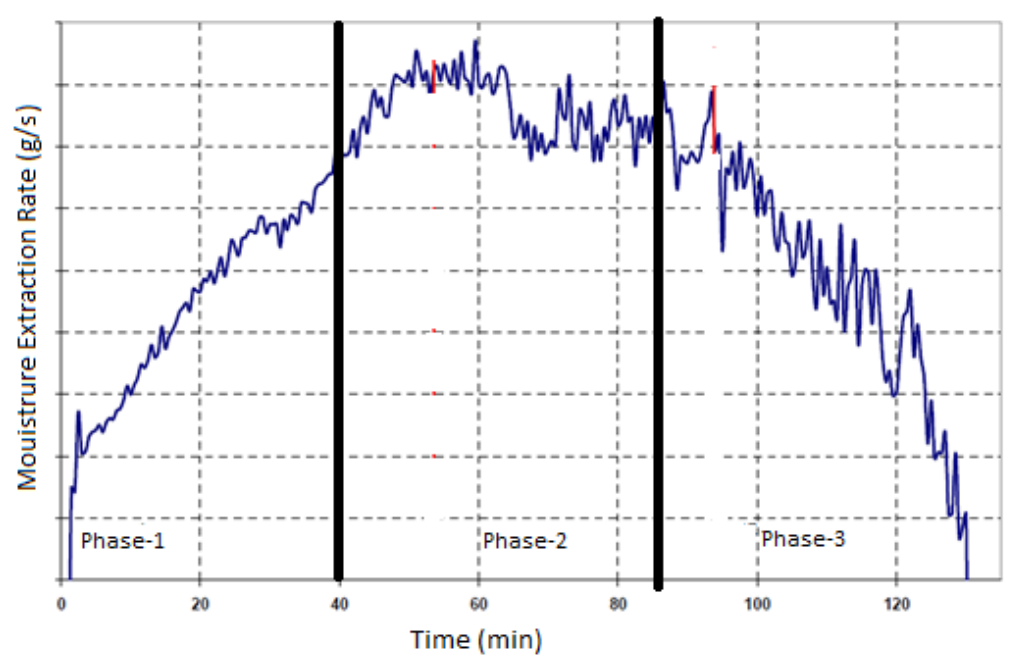

Figure 3: Moisture extraction rate variation in drying cycle.

\subsection{Effect of air inlet relative humidity (RH \%)}

Effect of air inlet relative humidity (RH \%) on dehumidification efficiency on plain fin evaporators with hydrophobic coating has been represented in Figure 4. As can be seen in Figure 4, increase in the inlet air relative humidity increases the dehumidification efficiency of the evaporator coil. This effect has also been observed in wavy fin and hydrophilic coated evaporators. 


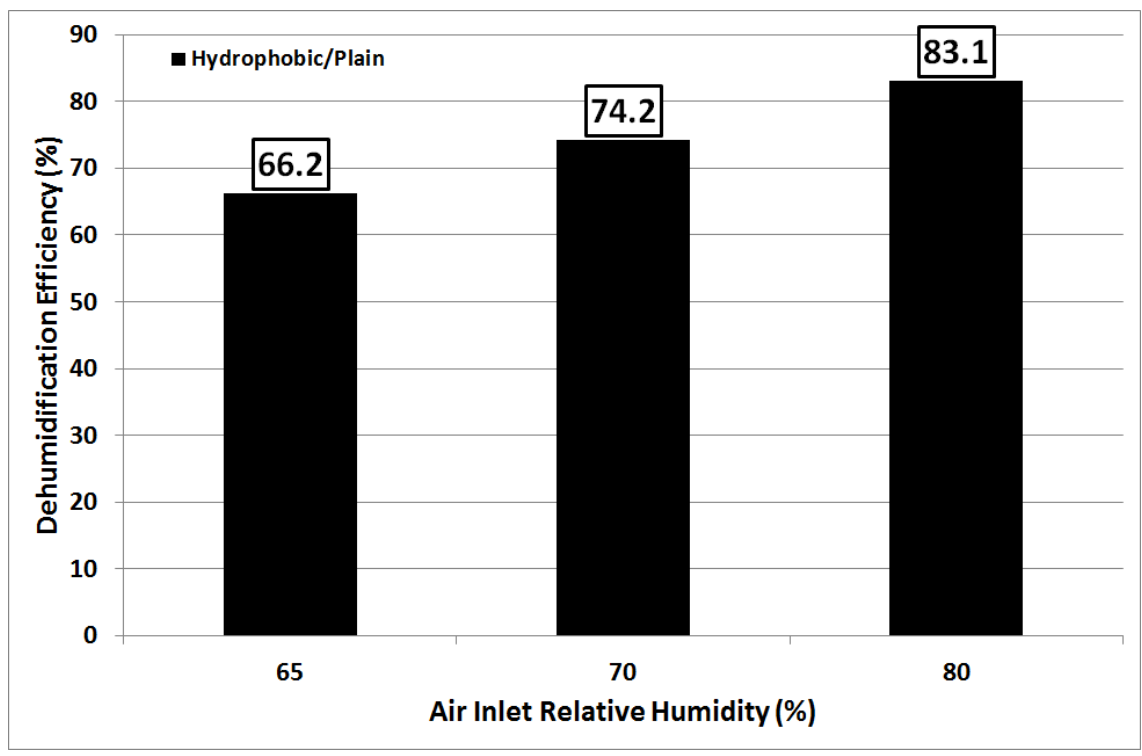

Figure 4: $\quad$ Effect of air inlet relative humidity on dehumidification efficiency on plain fin evaporators with hydrophobic coating.

\subsection{Effect of fin coating and fin surface structure}

Variation of dehumidification efficiency with fin coating on plain-finned evaporator is shown in Figure 5. Considering 65\% air inlet relative humidity ratio, dehumidification efficiency of hydrophilic coated evaporator is higher than hydrophobic coated type. However, for relative humidity values higher than $65 \%$, this trend has changed in opposite direction which results in higher dehumidification efficiency for hydrophobic coated coil. This can be explained by the water contact behaviour of the coated surface. In hydrophilic coated surfaces, due to the spread of water on the fin surface, water creates a thin film layer. Increase of the $\mathrm{RH} \%$ increases the water film thickness of the layer. Thus heat and mass transfer capability of the evaporator decreases which also results a decrease in the overall dryer performance.

In hydrophobic surfaces, contact angle between the coated surface and the water increases due to surface tension which pushes water to create a droplet form on the surface. Depending on the increase of the relative humidity of the inlet air, droplets tend to enlarge on the fin surface. This increases the gravitational force acting on the droplets which helps them to drain from the coil surface in an easier way compared to the hydrophilic coated surfaces. This effect has a positive role on heat and mass transfer performance of the evaporator which can be observed on the dehumidification rate and moisture extraction rate. Furthermore, Wang et al. [2] highlighted the similar results that droplets are combined to form larger droplets on the fin surface and the water drainage increases. 


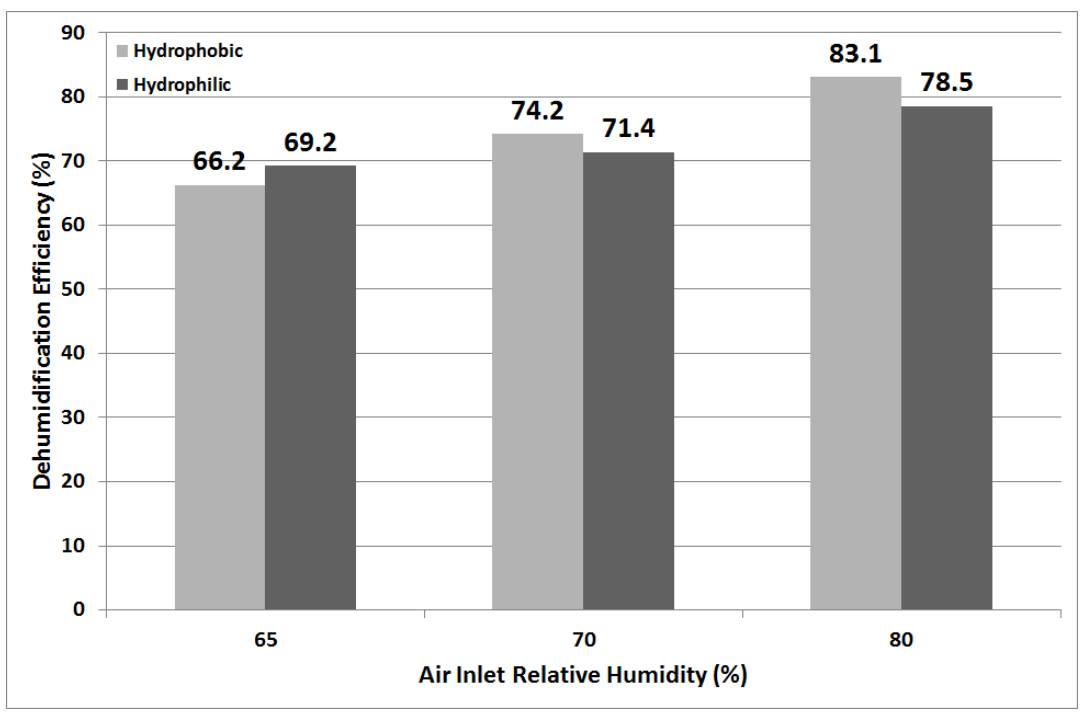

Figure 5: Change of the dehumidification efficiency value for plain fin type heat exchanger, depending on the coating type.

Figures 6(a) and 6(b) represent effect of the fin structure and the coating type on dehumidification efficiency under different inlet air relative humidity values. For air inlet humidity values over $70 \%$, hydrophobic coated evaporator with plain fin has better dehumidification performance compared to the hydrophilic coated one. Also, for both hydrophilic and hydrophobic coated surfaces, evaporator with plain fin has better dehumidification performance compared to wavy one for all air inlet humidity ratios. This result can be explained with the water drainage capability of the fins. As shown in Figure 7, friction force acting on the water droplet on the wavy fin surface is bigger than the one in the plain fin due to the water flow path on the fin.

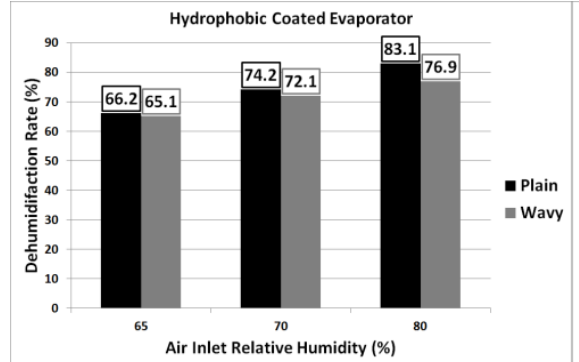

6(a)

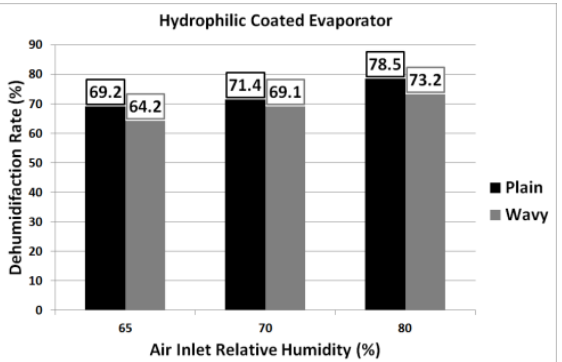

6(b)

Figure 6: Change of the dehumidification efficiency value for hydrophobic 6(a) and hydrophilic 6(b) coated fin type heat exchangers, depending on fin type. 


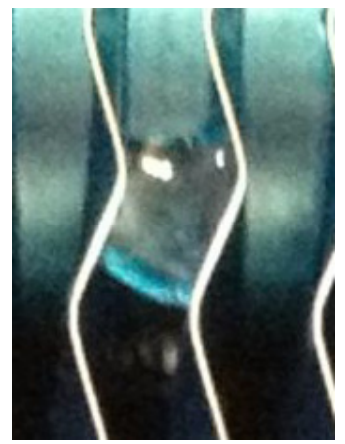

Wavy fin type evaporator

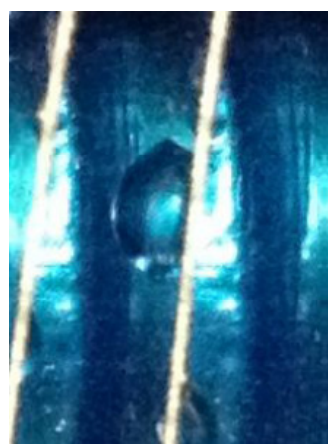

Plain fin type evaporator

Figure 7: Comparison of the water flow path on different fin types.

Dehumidification rate, MER, is also used to analyze the test results in another aspect. As represented in Figure 8 when air inlet RH\% increases, MER value increases. Moreover, maximum MER value is reached with the hydrophilic coated plain fin type evaporator. The reason is that the water flow path on the plain-fin evaporator is shorter than the wavy-fin evaporator. Figure 8 also shows that fin structure is more dominant than fin coating type when considering MER value. Besides, for air inlet $\% \mathrm{RH}$ values over $70 \%$, MER is higher in plain finshaped evaporator compared to the hydrophobic one.

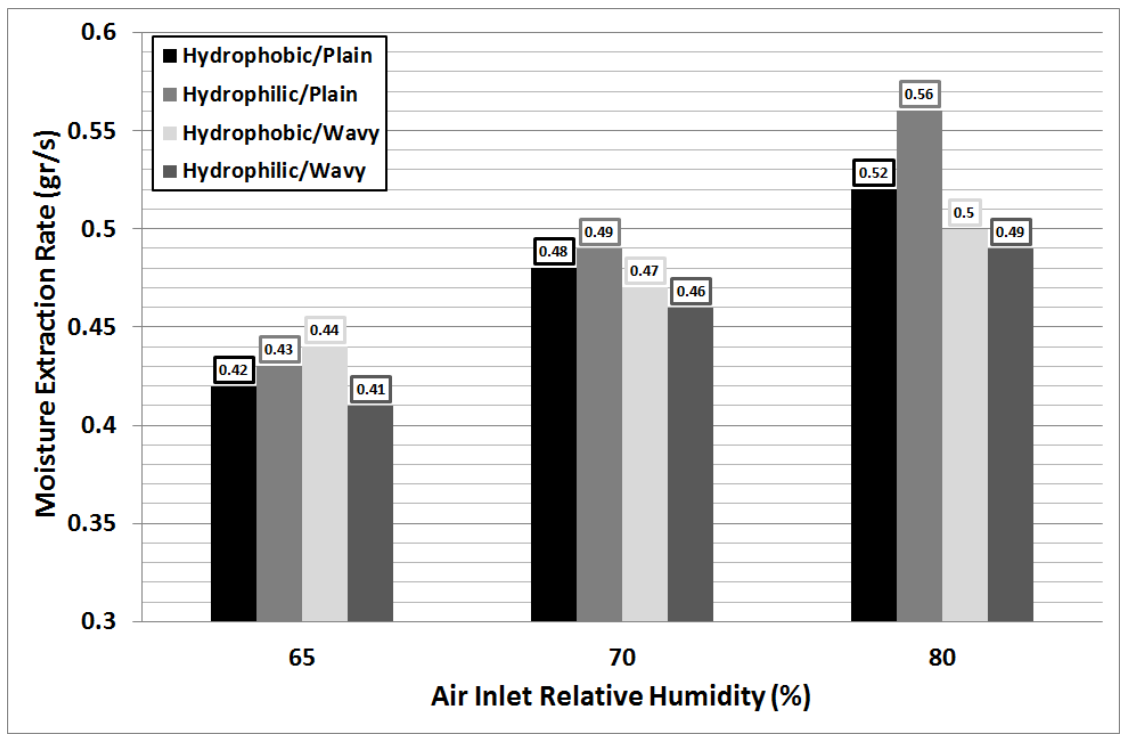

Figure 8: Change of moisture extraction rate for evaporators, depending on the fin structure and fin surface type. 


\section{Results}

The following conclusions have been obtained.

- Air inlet relative humidity has a major effect on condensation rate and condensation efficiency, for heat pump evaporator. As the air inlet relative humidity increases, condensation rate and efficiency increases.

- Considering the fin coating for wavy fins, evaporators with hydrophobic coating have better performance compared to the hydrophilic coating in terms of condensation rate and efficiency.

- Considering the fin coating for plain fins, evaporators with hydrophilic coating have better performance compared to the hydrophobic coating in terms of condensation rate and efficiency.

- For the evaporators with hydrophobic coated plain and wavy fins, plain type fins have better performance compared to the wavy one in terms of condensation rate and efficiency. Same results have been obtained for the hydrophilic coatings.

\section{Acknowledgement}

This project was funded by Arçelik A.Ş.

\section{References}

[1] A.S. Huzayyin, S.A Nada and H.F Elattar Air-side performance of a wavyfinned-tube direct expansion cooling and dehumidifying air coil. International Journal of Refrigeration 30, pp. 230-244, 2007.

[2] Chi-Chuan Wang, Yur-Tsai Lin, Kuei-Chang Hsu and Yu-Juei Chang, Performance of rectangular fin in wet conditions: Visualization and wet fin efficiency. Journal of Heat Transfer Vol. 123, pp. 827-836, 2001.

[3] Worachest Pirompugd, Chi-Chuan Wang and Somchai Wongwises, Correlations for wet surface ratio of fin-and-tube heat exchangers. International Journal of Heat and Mass Transfer 53, pp. 568-573, 2010.

[4] Xiaokui Ma, G. Ding, Y. Zhang and K. Wang, Airside heat transfer and friction characteristics for enhanced fin-and-tube heat exchanger with hydrophilic coating under wet conditions. International Journal of Refrigeration 30, pp. 1153-1167, 2007. 